\title{
CONTEXTUALIZANDO $O$ LÚDICO EM SALA DE AULA: A IMPORTÂNCIA DO BRINCAR NA EDUCAÇÃO INFANTIL ENTRE 03- 05 ANOS
}

\section{ARTIGO ORIGINAL}

NASCIMENTO, Josefa de Barros Barbosa do ${ }^{1}$, SILVA, Miriam Maria $\mathrm{da}^{2}$, MARONES, Bruno ${ }^{3}$

NASCIMENTO, Josefa de Barros Barbosa do. SILVA, Miriam Maria da. MARONES, Bruno. Contextualizando o lúdico em sala de aula: a importância do brincar na educação infantil entre 03-05 anos. Revista Científica Multidisciplinar Núcleo do Conhecimento. Ano. 06, Ed. 10, Vol. 01, pp. 72-95. Outubro 2021. ISSN: 2448-0959, Link de

acesso:

https://www.nucleodoconhecimento.com.br/educacao/contextualizando-o-ludico,

DOI: 10.32749/nucleodoconhecimento.com.br/educacao/contextualizando-o-ludico

\section{RESUMO}

Este estudo teve como objetivo investigar a importância do brincar e do brinquedo no processo de ensino aprendizagem, analisando as concepções que os educadores têm a respeito do lúdico frente à formação das crianças. O campo de pesquisa fora numa Escola Municipal de Jaboatão, e teve como participantes três professoras. Onde utilizamos uma pesquisa de base qualitativa, na qual comprovamos que as brincadeiras e os brinquedos proporcionam o desenvolvimento em todos os aspectos. Os resultados indicaram que a ludicidade contribui de forma positiva na formação da criança, na construção de novos saberes e no crescer sadiamente, que essa prática quando inserida na sala de aula pode promover

\footnotetext{
${ }^{1}$ Concluinte do Curso de Licenciatura em Pedagogia pela Faculdade Joaquim Nabuco - Recife.

${ }^{2}$ Concluinte do Curso de Licenciatura em Pedagogia pela Faculdade Joaquim Nabuco - Recife.

${ }^{3}$ Orientador. Mestre em Educação pela Universidade Federal de Pernambuco; Especialista em História do Nordeste pela Universidade Católica de Pernambuco; Graduado em História pela Fundação de Ensino Superior de Olinda.
}

RC: 98339

Disponível em:

https://www.nucleodoconhecimento.com.br/educacao/contextualizando-o-ludico 
transformações nos comportamentos, transportando momentos de afetividade ao longo do tempo, assim quem brinca aprende a construir a cultura da solidariedade, deixando o individualismo e permitindo a convivência sadia.

Palavras-chave: O brinquedo, a brincadeira, Ensino aprendizagem desenvolvimento Infantil.

\section{INTRODUÇÃO}

No atual trabalho aborda-se a questão do brincar como fonte de desenvolvimento e, construção de saberes na primeira infância. Sabe-se que a criança é um ser em formação e é necessário que receba estímulo ao longo da educação infantil, pois é um momento em que o sujeito aprende valores sobre moralidade, respeito e a cima de tudo crescem como ser humano. Esse foi um dos motivos que nos despertou aprofundar o estudo a luz da ação lúdica na formação do indivíduo, suas descobertas e a forma de agir na sociedade -RCNEI, (1998).

Esse estudo tem como objetivo geral investigar a importância do brincar como ferramenta fundamental na aprendizagem dos alunos da educação infantil, assim sendo os objetivos específicos: historicizar a educação infantil no Brasil, investigar o conceito de ludicidade e ainda analisar a contribuição de atividades lúdicas na educação infantil.

Os teóricos apresentados, neste estudo, Antunes (2012), Kishimoto (2006, 2011) G.Brougére (2010), Linn, Susan (2010) e entre outros estudiosos revelam que, os brinquedos e as brincadeiras proporcionam momentos de grande alegria, além de ser um fato social que possibilita um aprendizado de maneira gostosa e saudável ao público infantil, sendo por meio do brincar que se podem conhecer diferentes caminhos, para a convivência na sociedade e a construção de novos saberes e, certamente será brincando que se educam sujeitos resilientes.

A ludicidade na educação infantil possibilita o aprendizado significativo, criativo e inventivo, já que propícia a troca de saberes de maneira prazerosa em que a criança

RC: 98339

Disponível em:

https://www.nucleodoconhecimento.com.br/educacao/contextualizando-o-ludico 
possa entender as regras durante as brincadeiras e, certamente são atividades que promovem habilidades, físicas, cognitiva, motora, além de contribuir para aceitação e o respeito ás normas, contribuindo na vida social, na afetividade, na criatividade e na relação consigo mesmo e com o outro, proporcionando de forma gradual, a formação de seres participativos, reflexivos, ativos, cooperativo, ocupando seu lugar na sociedade, além de favorecer a liberdade, autonomia, sabendo apenas que estão brincando. As brincadeiras são importantes, pois impulsionam processos de aprendizagem, desenvolvendo, a imaginação e invenção, intensificando e permitindo o desenvolvimento, promovendo o crescimento por meio do brincar, auxiliando no processo de ensino aprendizagem.

Os brinquedos e as brincadeiras são primordiais na vida das crianças, pois quem brinca se desenvolve e cresce com mais liberdade, construindo então um mundo ramificado de possibilidades, lado a lado com o lúdico. Wallon (apud BROUGÉRE, 2010, p.104), discute que.

A brincadeira é todos os comportamentos de descoberta da criança. Porém os adultos brincam com as crianças. A criança entra progressivamente na brincadeira do adulto de quem ela é inicialmente o brinquedo, se envolve em atividades que tem forte teor cultural.

Discute-se que, a criança a princípio serve de brinquedo para o adulto, no qual se brinca com ela dando origem a uma ação lúdica e, com essa atitude a brincadeira vai sendo construída e, a criança aprende gradualmente a brincar, entrando na brincadeira e, assim sendo, seus comportamentos e descobertas vão se originando no conjunto dessa cultura e, o aprendizado ocorre justamente ao entender e dominar e, depois a criança brinca interage, se comunica com o outro e em seguida reproduz a experiência anterior, transportando o desenvolvimento motor, sociocognitivo emocional e afetivo.

Sabe-se que os brinquedos fazem parte do cotidiano da criança e, vem desde outrora contribuindo para o desenvolvimento da humanidade que com o passar do 
tempo ganharam cores, formas e texturas, objeto manipulável que a meninada adora interagir com ele, certamente é no brincar que alimenta a inteligência infantil e, provavelmente suas perspectivas, dando oportunidades para novos relacionamentos e interação no meio que a rodeia. Além disso, as brincadeiras são ferramentas importantíssimas para ser oferecida ao sujeito desde cedo e, em especial na educação infantil. (BROUGÉRE, 2020).

A cultura lúdica não pode ser esquecida, ela deve ser inserida no espaço escolar, e vir repleta de significado, bem como representada pelo brincar. É necessário que o profissional que atua com crianças menores tenha em mente o quanto o brincar é relevante, no processo de ensino aprendizagem, entendendo e compreendendo, que a troca de saberes embasada na brincadeira, motiva e incentiva a criança, a aprender e se desenvolver brincando, que a ludicidade não será apenas uma simples brincadeira, porém ela perpassa o brincar. $O$ papel lúdico favorece a diversão, alegria e o prazer, o brinquedo é a mediação de qualquer aprendizado que satisfaça o sujeito em seu crescimento, alimentando o seu universo e contemplando o processo de aprendizado, permitindo de maneira gradual a construção da criticidade. (KISHIMOTO, 2011).

Tomando como base o Referencial Curricular Nacional Para Educação Infantil, quando diz que "a brincadeira favorece a auto-estima das crianças, auxiliando-as a superar progressivamente suas aquisições de forma criativa".

O professor dessa faixa etária deve perceber que o lúdico é essencial, no desenvolvimento da criança em todos os aspectos e, não se limitando a trabalhá-lo na sala de aula. Portanto elencamos o seguinte questionamento: Qual a Importância do Brincar na Educação Infantil?

Sabe-se que as crianças gostam de brincar, logo o professor deve recorrer a sua criatividade, desenvolvendo atividades lúdicas, pois é no brincar que a criança aprende a conviver em grupo solidariamente, estreitando laços de amizade e ampliando o seu conhecimento de mundo. E, provavelmente construindo um 
caminho de confiança com o outro, levando as experiências vividas ao longo do tempo.

O brincar é um caminho que não escolhe faixa etária, pelo contrário as crianças vão interagindo em meio a tanta brincadeira e brinquedos, analisam-se com isso que a o brincar é linguagem infantil que faz surgir ideias junto às crianças e desse jeito, elas aprendem brincando, já que esse fenômeno na mão de uma criança nunca é algo terminado, geralmente dá origem a nova atividade, ou mesmo a outro brinquedo, percebe-se que a cultura lúdica é foco de união entre o universo infantil e viabilizando o estreitamento de amizades, a construção de valores, de experiências, convivência harmônica e de carinho pela outra pessoa.

Os brinquedos e as brincadeiras são de grande valia na vida das pessoas e, em especial das crianças menores, pois quem se desenvolve brincando cresce e aprende alegremente.

Verifica-se que o brincar propõe novas possibilidades ao sujeito, que busca participar e interagir com o meio no qual faz parte, a brincadeira é uma cultura que surgira lado a lado com a evolução da sociedade e, certamente continua avançando nos dias atuais.

Incorporado nesse contexto acredita-se que, com base no tema, A Importância do Brincar na Educação Infantil entre 03-05 anos? Bem como, no conhecimento da literatura atual e, na pesquisa bibliográfica e de campo deixando nítido o quanto o brincar é benéfico ao processo de ensino aprendizagem.

A contribuição das brincadeiras é linguagem infantil e por isso são ações de vivência, comunicação, de momentos divertidos, em que o sujeito, recria, reinventa, constrói, descobre, aprende, sonha, elevando, motivando e aguçando a curiosidade da criança, viabilizando outros entendimentos como: atividade grupal, interação social, além de proporcionar o desenvolvimento em todos os aspectos. 
Assim espera-se com a atual pesquisa poder contribuir para uma melhor compreensão da importância dos brinquedos e das brincadeiras no processo de aprendizagem e em especial da educação infantil. Que esse trabalho também sirva de ferramenta de apoio para futuros formandos que decidirem investigar essa temática.

\section{PERCURSO METODOLÓGICO}

Compreendem-se por metodologia a organização de estratégias com o objetivo de orientar o estudo nas mais diversas etapas. Para Andrade (2010, p.116), "Metodologia é o conjunto de métodos ou caminhos que são percorridos na busca do conhecimento". Decidimos escolher por esta abordagem, ao despertar o interesse de conhecer de maneira atenta e cuidadosa, os argumentos de vários teóricos e pesquisadores apresentados ao longo de nossa formação como: Kishimoto, (2006 e 2011) G. Bruogére, (2010), Antunes, (1012), Linn, Susan, (1010), e entre outros, que nos apresentaram saberes valiosos sobre a importância da ludicidade no processo de ensino aprendizagem. A abordagem é de base qualitativa, a mesma se caracteriza por ser uma atividade investigativa, flexível, considerando a subjetividade, onde não se podem quantificar os sujeitos. (TRIVINÕS, 1987).

Essa abordagem tem como meta investigar a relevância do brincar e do brinquedo na educação infantil.

A base de dados foi através da abordagem de campo, segundo Andrade (2010, p.112). "A pesquisa de campo baseia-se na observação dos fatos efetuando a coleta de dados no local". E da seleção da bibliografia sobre o assunto, que fornecerá os dados necessários para a realização do artigo. A pesquisa bibliográfica se refere à fonte de papel seja ela primaria ou secundária onde utiliza-se livros e outros documentos Andrade (2010). Tendo em mãos as obras que poderão ser úteis e a coleta de dados que fora realizada numa escola municipal de Jaboatão, ela acolhe um público reduzido de educandos, educação infantil e ensino fundamental I.A mesma tem seis salas de aula que funcionam em dois turnos, manhã e tarde.

RC: 98339

Disponível em:

https://www.nucleodoconhecimento.com.br/educacao/contextualizando-o-ludico 
Decidimos realizar nossa pesquisa nessa escola por conhecer a instituição e por ser próximo de nossa residência.

O instrumento utilizado na atual abordagem fora uma entrevista semiestruturada que utilizamos papel e grafite para transcrever o que foi dito, pois a entrevista foi simplesmente anotada tal quais as palavras das entrevistadas. Segundo Andrade (2010), entrevista "Constitui um instrumento eficaz de recolha de dados fidedignos para elaboração de uma pesquisa, desde que seja bem elaborado, bem realizado e interpretado". Esse tipo de abordagem requer certos cuidados, para isso o entrevistador deve organizar o material necessário para a coleta dos dados. O trabalho fora realizado com professores que trabalham na rede municipal de educação infantil em Jaboatão, todas graduadas em pedagogia atuando na área a mais de dez anos, com idade entre 35 e 40 anos e teve como técnicas a observação e análise dos dados que foram interpretados a partir das perguntas que fizemos as participantes, três professoras, assim nomeadas que trabalham na rede de educação infantil de Jaboatão.

\section{A EDUCAÇÃO INFANTIL NO BRASIL}

A Lei no 9394/96 em seu art. 29, Lei de Diretrizes e Base da Educação Nacional.

A educação infantil é compreendida como primeira etapa da educação básica e, tem como finalidade o desenvolvimento integral da criança de zero a cinco anos de idade em seus aspectos físicos, afetivo intelectual, linguístico e social, complementado a ação da família e da comunidade.

Sabe-se que a motivação que primeiramente a criança recebe da família é importante para o seu desenvolvimento durante essa etapa é crucial para a formação integral do sujeito, devendo respeitar as características da faixa etária e, também as capacidades, cognitivas, físicas, afetiva e social, vendo a infância como um ser histórico em desenvolvimento capaz de se desenvolver através dos estímulos recebidos do meio que a cerca. 
Porém sabe-se que não foi sempre assim, que aconteceu a educação infantil, de acordo com os estudos dos pesquisadores, Pinheiro et al, (2014, p.73).

No início do século passado, no Brasil o que tínhamos eram as chamadas "creches" que visavam atender as crianças de mães que trabalhavam fora de casa e o atendimento envolvia basicamente a alimentação, higiene e segurança física tendo assim um caráter puramente assistencialista apenas.

Reflete-se um sentimento de que no início do século XX à criança recebia apenas os cuidados elementar para sua sobrevivência, se limitando somente numa educação que não visava à transformação da realidade social. Kishimoto (2011, p.21) assevera que

Cada cultura tem maneiras de ver a criança de tratar educar. Entre as antigas concepções, a criança, vista como homem em miniatura, revela uma visão negativa: a criança é um ser inacabado, sem nada específico e original sem valor positivo.

Percebe-se que a criança não era vista como tal e sim, como um adulto pequeno, sendo incapaz de pensar vivendo num mundo não infantil. Mas essa visão de infância aquela que sufocava, retraia mínima, que recebia educação puramente moral, por meio dos educadores religiosos criando seres irracionais impossível de se desenvolver o espírito crítico. Essa realidade passa a sofrer mudanças com o passar do tempo.

A constituição Federal de 1988, a educação infantil passou a ser entendida como necessária e direito de todos, a partir desse momento a criança passa a ser incluída numa política educacional seguida por uma pedagogia para transformação.

Desde a constituição Federal de 1988, do Estatuto da Criança e do Adolescente de 1990 o (ECA) e da LDB Lei de Diretrizes e Base da Educação Nacional, a educação infantil abrange crianças de zero a cinco anos, que ver essa etapa como primordial para o desenvolvimento da infância. Bachilard (apud KISHIMOTO, 2011, p.22), "considera as imagens que sobrevivem da infância como resultados de dois elementos: a memória e a imaginação". Entende-se que a recordação e a idealização são povoadas na cultura lúdica alimentando o pensamento fértil. A 
criança nessa perspectiva é um ser em pleno desenvolvimento, com suas percepções, características, interesses, sentidos, criatividades e construindo sua ótica de mundo.

A criança diante das leis acima apresentadas é vista como um ser histórico, social e, em pleno desenvolvimento, por meio dessa perspectiva a sociedade fica mais sensibilizada da importância da convivência da primeira infância, promovendo uma educação para a cidadania, objetivando fazer de cada sujeito um agente de transformação. De acordo com Kishimoto (2011, p.22). "A infância é também a idade do possível. Pode-se projetar sobre ela a esperança de mudança de transformação social e renovação moral". A criança é vista como símbolo da transformação e a luz da renovação em Kishimoto. Assim, para que se eduquem pessoas com espírito democrático e que venham contribuir para o bem da sociedade é, necessário também que se reflita profundamente sobre a História de cada sujeito, definido por Pinheiro et al. (2014, p.105). "Educar para a cidadania é adotar uma postura e, fazer escolhas. É despertar para as consciências dos direitos e deveres". Analisa-se sobre o pensamento citado que se educa para que o outro vá ao encontro da justiça, do respeito e deveres mais relevante, se faz necessário cultivar a educação para o exercício da cidadania, pois se entende que, só será construída a cidadania se educar na cidadania.

\section{A BRINCADEIRA E O DESENVOLVIMENTO INFANTIL}

Verifica-se, diante dos discursos que, brinquedos e brincadeiras surgiram com o intuito de auxiliar o homem na interação com o meio e, em seu desenvolvimento, a criança que brinca quando pequena é mais feliz e aprende a perceber gradualmente o valor dos objetos (brinquedos), Vygotsky (apud KISHIMOTO, 2011),em suas pesquisas asevera que.

Só brincando é que a criança vai começar a perceeber o objeto não da maneira como ele é, mas como desejaria que fosse. Na aprendizagem formal isso não é possível,mas no brinquedo isso acontece ,porque é onde os objetos perdem a sua força determinadora ,A criança não vê o objeto, mas Ihe confere um novo significado. (p.68).

RC: 98339

Disponível em:

https://www.nucleodoconhecimento.com.br/educacao/contextualizando-o-ludico 
Percebe-se de forma axiomática que os objetos ao caí na mão de uma criança valem e significam outra coisa, pois ela dar outro sentido e, esse mesmo ganha vida e até mesmo outra denominação, onde os gestos falam enquanto a criança brinca e vai imaginando, simbolizando cada brinquedo, quando tem um material diferente em seu poder seu imaginário borbulha buscando sempre algo diferente daquilo que ela almeja que fosse. As atividades lúdicas podem permitir a construção de novos conhecimentos e mudanças, pois cria situações reais no pensamento de quem brinca, além de ocorrer, portanto, a formação de valores, por isso os brinquedos e as brincadeiras são recintos de aprendizado. De acordo com o Referencial Curricular Nacional Para Educação Infantil, (1998).

No ato de brincar, os sinais, os gestos, os objetos e os espaços valem e significam outra coisa daquilo que aparentam ser. Ao adotar outros papéis na brincadeira, as crianças agem frente à realidade de maneira não-literal, transferindo e substituindo suas ações cotidianas pelas ações e características do papel assumido, utilizandose de objetos substitutos. (p.27).

Analisa-se que, no momento das brincadeiras e dos brinquedos são ações que descortinam algo diferente, porque é brincando que a criança viaja no mundo de imaginação e descoberta, permitindo que ela represente os papéis que escolheram para brincar fazendo uma viagem no tempo e construindo valores, que só os jogos e as brincadeiras podem the oferecer. Tal qual Piaget fala:

As culturas lúdicas estão intimamente ligadas a sequência dos estágios divididos por ele e acompanha o desenvolvimento da inteligência do indivíduo o brinquedo é um mundo repleto de representações, que representa o carinho e a imitação, (2011, p.25).

Sabe-se que os avanços são identificados pelo aquilo que de melhor o sujeito fizer, pois a cada etapa ele vai se desenvolvendo gradualmente e, com certeza, os jogos e as brincadeiras proporcionam o crescer juntos.

Ainda refletido sobre o pensamento acima as brincadeiras trazem em sua natureza um potencial analítico, estimula o aprendizado do aluno com enfoque aqui na

RC: 98339

Disponível em:

https://www.nucleodoconhecimento.com.br/educacao/contextualizando-o-ludico 
educação infantil, são ferramentas que podem ser abordados com vários temas como, as cores, os animais, as frutas e entre outros conteúdos. Por isso o brincar é necessário e, o sujeito aprende desde muito cedo os valores de cada objeto e, que o bacana mesmo é brincar numa sintonia de solidariedade com o os demais. De acordo com Referencial Curricular Nacional para Educação Infantil (1998).

O estabelecimento de um clima de segurança, confiança, afetividade, incentivo, elogios e limites colocados de forma sincera, clara e afetiva dão tom de qualidade da Interação entre adultos e crianças. O professor, consciente de que o vínculo é, para a criança, fonte contínua de significações, reconhece e valoriza a relação interpessoal. (p. 49).

Verifica-se que as atividades lúdicas despertam diversos saberes na criança, pois elas observam, participam das brincadeiras e, é nesse embale pela qual os pequenos adquirem e aprimoram suas capacidades cognitivas, socializando e interagindo com o meio que a rodeia, percebendo também a sinceridade e a qualidade da interação entre os autores, adulto e criança é ponto positivo para o desenvolvimento infantil. Segundo Piaget (apud ALMEIDA, 1974).

As brincadeiras tornam-se mais significativas à medida que a criança se desenvolve, pois a partir da livre manifestação de materiais variados, ela passa a reconstruir objetos e reinventar as coisas, o que já exige uma "adaptação" mais completa. Essa adaptação, que deve ser realizada pela infância consiste numa síntese progressiva da assimilação com a acomodação. É por isso que pela própria evolução interna, os jogos (brincadeiras) das crianças se transformam pouco a pouco em construções adaptadas, exigindo sempre mais do trabalho efetivo, a ponto de nas classes elementares de uma escola ativa, todas as transformações espontâneas ocorrem entre o jogo e o trabalho. (p.25).

Verifica-se que a criança que contar com recursos que provavelmente ajudem a explorar sua criatividade por meio do jogo e das brincadeiras tanto social como cognitivo, será um adulto sem dificuldades para encontrar seu caminho e, que melhor ainda, desfrutará fazendo seu trabalho com gosto e dedicação. Com os brinquedos as crianças internalizam valores, relacionando-se harmoniosamente, tanto com as pessoas a sua volta como também com os objetos e naturalmente com meio ambiente. Para Kishimoto (2011). 
O uso do brinquedo/jogo educativo com fins pedagógicos remete-nos para a relevância desse instrumento para situações de ensino aprendizagem e desenvolvimento infantil. Se considerarmos que a criança pré-escolar aprende de modo intuitivo, adquire noções espontâneas, em processos interativos, envolvendo o ser humano inteiro com suas cognições, afetividade, corpo e interações sociais, o brinquedo desempenha um papel de grande relevância para o desenvolvê-la. Ao permitir à ação intencional (afetividade), a construção de representações mentais, (cognição), a manipulação de objetos e desempenho de ações sensório motoras (físico) e as trocas nas interações (social), o jogo contempla várias formas de representação da criança ou suas múltiplas inteligências, contribuindo para a aprendizagem e 0 desenvolvimento infantil. (p.40-41).

O brinquedo educativo é compreendido como aquele que contribuí para o desenvolvimento saudável e, as brincadeiras são manifestações diante do objeto, (brinquedo) a brincadeira é, portanto algo que se relacionam lado a lado com o brinquedo, onde a criança brinca interage da vida e sentido a cada peça, sendo que as brincadeiras estão relacionadas com o que se desenvolve no ato de brincar, "o faz de conta", as brincadeiras de roda, a música e entre outras. Brinquedos, brincadeiras ou jogos educativos sejam atividades deleite, escolhido por vontade própria, ou mesmo quando assume a função educativa, o bacana é que são grandes ferramentas para o processo de ensino aprendizagem, principalmente junto à educação infantil. Almeida (2003, p. 33) dialoga que: "o conteúdo do brinquedo não determina a brincadeira da criança, mas o ato de brincar que revela o conteúdo do brinquedo". Verifica-se que é no brincar que o sujeito realiza as descobertas, desenvolvendo as habilidades, física, cognitivas e entre outras. Endossado por Áries (apud KISHIMOTO, 1978).

\begin{abstract}
Identifica o brincar como uma especialidade da infância na icografia de tempos passados, renomados pintores radicados no Brasil mostraram a imagem da criança brasileira em suas maravilhosas telas, na obra ilustrada de Jordão (1979), denominada A Imagem da criança na pintura brasileira, destaca-se o brincar como típico da criança... De pôr a mão nos objetos, como brinquedos, instrumentos e entre tantos outros. (p.77).
\end{abstract}

Diante do relato acima, o brincar é característico da criança é uma linguagem meramente infantil e que, a cada nova brincadeira, uma emoção contagiante, portanto uma formação coroada de aspectos positivos, que envolve a criança aparecendo diante da interação sócio cultural e com os objetos que faz parte de seu

$\mathrm{RC}: 98339$

Disponível em:

https://www.nucleodoconhecimento.com.br/educacao/contextualizando-o-ludico 
universo, desencadeando a brincadeira e possibilitando novas experiências, suporte de ação e atitude lúdica.

As crianças amam brincar e, é por meio dela que o sujeito será capaz de promover verdadeiras amizades, vivendo diferentes relações, onde há um ambiente lúdico, sem dúvida há também alegria, sorrisos, felicidades, essa sonoridade, aguçam o colorido do meio e do espaço, que tem como enfeite os brinquedos as brincadeiras, tendo em vista o sucesso do desenvolvimento e de capacidades desde os primeiros dias de vida. $O$ brincar estimula à imaginação e a criatividade, incentivando o processo de aprendizagem.

\section{O JOGO E A EDUCAÇÃO INFANTIL}

Para Kishimoto (2011) o jogo não é uma atividade de fácil explicação, pois o termo jogo pode ter diversos entendimento dependendo do contexto sociocultural, já que ao se falar de jogo, pode-se estar se referindo a jogos de adultos, crianças e até mesmo de animais, contar estórias, amarelinhas, brincar de representar papéis, de construir algo e entre uma imensidão de brincadeiras, que tento a mesma denominação tem certamente suas particularidades. Compreende-se que, o jogo é um objeto que representa algo, permitindo que a criança faça essa representação, imaginando , criando e reinventando situações, (desenhos, imagens), permitindo à reflexão, socialização, a convivência grupal e a formação de pessoas éticas desde muito cedo.

Em nossa abordagem as professoras revelaram que utilizavam atividades que envolviam jogos e brincadeira, já que é instrumentos que viabiliza a socialização do sujeito, logo lançar mão dessa categoria é motivar o sujeito a vencer obstáculos, perdendo a timidez e estreitando laços de amizades. Verificamos então que o brincar é um elo que abraça as relações cooperando e incentivadora no desenvolvimento infantil.

RC: 98339

Disponível em:

https://www.nucleodoconhecimento.com.br/educacao/contextualizando-o-ludico 
Ainda discutindo com Kishimoto (2011), na brincadeira de fingir a grande presença de situações fantasiosas, no dominó as regras permitem a movimentação das peças, brincar na areia de escultura simplesmente pela alegria e o prazer de sentir a areia escorregar pelas mãos, encher forminhas e esvaziar requer a satisfação de manipular o brinquedo, essas ações promovem habilidades manual, cognitiva e social para realizá-las.

O jogo é um tipo de brincadeira em que o a criança internaliza diversos saberes e competências, dando possibilidades de participação nas brincadeiras, aonde ela gradativamente irá entender noções de regras, entra na brincadeira, espera sua vez compartilha momentos e, compreende o direito do seu parceiro, tanto o seu quanto o da outra pessoa, sabendo que ele poderá participar na próxima partida. É jogando e brincando que a criança passa de uma fase a outra exercendo movimentos mais específico, utilizando para isso os sentidos, manipulando com as mãos tudo que estiver ao seu alcance, mexe nos objetos, adora rasgar, numa comunicação inteligente, aprimorando sua coordenação e aprendendo conceitos de maneira criativa. De acordo com Antunes (2012).

Os jogos em linhas gerais envolvem... O reconhecimento de objetos diferentes. Permitindo associação, comparação, padrões e relacionamento entre eles. A partir dos três anos de idade. Toda criança possui diversas noções de espaços, produto do mundo que explora e que progressivamente, vão permitindo a criação de formas de representação (imagens, desenhos, palavras) desse mundo exploram conceitos de quantidade, tempo, causa e efeito, utiliza símbolos abstratos para representar objeto concreto, passando a sugerir o uso de habilidades na resolução de programas lógicos e utilizando diversas peças (lego) para resolver desafios que envolvam a construção de objetos. (p.22-23).

Entende-se que diante dos jogos, a criançada aprende a valorizar-se e também demonstra valor pelo colega, fazendo brotar os sentimentos, harmonizando o grupo e os interesses com os amigos, é um tema que contribui de forma satisfatória para vencer os obstáculos que pode vir a surgir durante as brincadeiras e, aprendendo a brincar, explorando a inteligência infantil, numa dinâmica dotada de significado. E,que o crescimento do sujeito permeado com jogos e brincadeiras, motiva o 
embalamento e o alcance de outros saberes fazendo com que a criança conquiste sua autonomia ao passar de uma etapa a outra. As professoras dialogaram que:

Os jogos trazem grandes contribuições na aprendizagem infantil, a criança se sente mais segura de se mesma, aprende a trabalhar em grupo desde cedo e seu desenvolvimento frui facilmente, passando a entender e respeitar regras na primeira infância, favorecendo de forma positiva no desenvolvimento da criança, tanto no contexto escolar, como também na relação com a comunidade, adquirido identidade de valor e promovendo amor ao próximo.

Segnundo G.Brougere (2010)."A brincadeira é a interação lúdica” As brincadeira com jogos têm sua importância,pois analisa-se nesse contexto que contruibui para a formação da cidadania,e a costrução de valores e de sujeitos críticos e reflexivos.O jogo é algo desafiador e instigante, já que é durante a atividade (jogo),que apredemse a solucionar possíveis problemas que possam vir a surgir no cotidiano.

\section{O BRINCAR DE FAZ DE CONTA}

De acordo com Correia (2013).

O amigo imaginário é uma forma de jogo simbólico. E esses jogos são expressões espontâneas que a criança usa para tentar entender os papéis dos adultos ela reelabora as experiências pelas quais passou alterando-as para entender os, desejos, vontades, interesses e necessidade. $O$ faz de conta é valioso para o equilíbrio emocional, pois dá aos pequenos como também a garotada a chance de transformar a realidade, seja para resolver possíveis problemas ou compreender dificuldades levando magia para o dia a dia.(p.20).

Percebe-se que a criança ao criar um amigo através do imaginário, ela está tentando compreender o mundo dos adultos, revelando e representando o real. Linn Susan (2010), em seus estudos relata que:

Certo dia estava a conversar com alguns adultos, em uma roda de conversa e de repente surge duas garotinhas, ao brincarem mergulham na fantasia, elas corriam e diziam uma à outra: corre, corre que La vem a Bruxa, sem se quer perceber os adultos que os cercava, a exuberância e a alegria daquelas criaturas eram algo digno de admiração. O fato de causar tanto prazer é razão mais do que suficiente para brincar, ocupar posição tão elevada em minha lista de paixões. Mas há muito mais. A capacidade de brincar é um mecanismo de sobrevivência. Muitos especialistas em desenvolvimento 
infantil concordam, por exemplo, que, brincar é o fundamento da exploração intelectual. (p.26).

A autora continua apresentando: "Aprecio e valorizo esse aspecto de brincar". Em uma profunda análise, entende-se que: a exploração do brincar é contagiante, é bom, causam as gargalhadas, na perspectiva dos estudos da Susan, as atividades lúdicas quando inserida no contexto infantil brota a verdadeira alegria no rosto da criança, ganham curvas, conquistam pontes e se transformam em algo inexplicável, e consequentemente apenas, sente-se a dimensão do contentamento, podendo compreender como a brincadeira se relaciona com a beleza e a saúde da mente, viajando num mundo estrelado transportando imaginariamente na vida social. Durante nossa abordagem as professoras revelaram que.

O brincar de faz de conta contribui na formação do imaginário, da invenção e da participação de papéis diversificados, esse tipo de brincadeira, incentiva a compreensão da vida adulta, já que a criança ao brincar de faz de conta passa a representar outra realidade saindo do real e vivendo um mundo de fantasia e imaginação, pois a criança cria ,recria, inventa, com isso o processo de aprendizagem ocorre em meio às brincadeiras, desenvolvendo o espírito cooperativo, auxiliando a imaginação, a aquisição da linguagem, aprendendo a lhe dar com os possíveis conflitos do dia a dia, além de construir amizades que levam para toda vida.

Nos diálogos das educadoras percebe-se que as mesmas têm uma percepção positiva da brincadeira de fingir, que essa brincadeira dar à criança a possibilidade de entender a vida de pessoas mais experientes, aguçando a sua curiosidade. Para Linn Susan (2010).

O faz de conta ou a brincadeira de fingir, que entendo por criar personagens de fantasia, imaginar diferentes realidades e transportar-nos para mundos imaginários diferentes daqueles em que vivemos. O faz de conta das crianças tem raízes na experiência únicas que elas têm com pessoas e eventos. Quando a oportunidade de brincar surge, a brincadeira aflora naturalmente nelas e serve como uma experiência primaria essencial a auto reflexão e expressão. (p.26-27).

Analisa-se que a brincadeira imaginária promove a convivência em diferentes tempos, à criança quando brinca de médico, passadeira e entre outras funções que essa categoria pode proporcionar, desenvolve a cognição, afetividade social do indivíduo. Piaget apud Kishimoto (2011 p.65-66). "Quando brinca, a criança assimila

$\mathrm{RC}: 98339$

Disponível em:

https://www.nucleodoconhecimento.com.br/educacao/contextualizando-o-ludico 
o mundo à sua maneira, sem compromisso com a realidade". O brinquedo nesse universo infantil ganha sentido e, quem o nomeia é a criança dando-lhe então diferentes significados. Durante nossa pesquisa de campo, pode-se constatar o quanto a brincadeira de fingir contribui na formação de seres críticos, assim como é possível ver no diálogo das professoras a seguir

O faz de conta contribui na formação do imaginário, da invenção e da participação de papéis diversificados, esse tipo de brincadeira, incentiva a compreensão da vida adulta, já que a criança ao brincar de faz de conta passa a representar outra realidade saindo do real e vivendo um mundo de fantasia.

No decorrer da pesquisa verificamos que, as educadoras têm uma concepção de que esse tipo de brincadeira possibilita a construção da imaginação, fazendo com que o sujeito possa representar múltiplos papéis, passeando num verdadeiro mundo de encanto, motivando o entendimento do cotidiano de pessoas mais experientes.

\section{O BRINQUEDO E A BRINCADEIRA}

O brinquedo é um objeto que age e interage com a criança diante da variedade de oportunidades, que o sujeito da análise é o desenvolvimento infantil, G. Brougére (2010), com isso o brinquedo é instrumento que constrói um espaço de interação com meio, já que ele é fruto da sociedade e traços de uma cultura que envolve as crianças nos ambientes.

O brinquedo, artigo descontraído, dialogando ainda com G. Bruogére é fonte comunicável, proporcionando destino diverso, pois quando a criança alcança um brinquedo, esse mesmo se transforma em brincadeira. Nessa ótica o objeto lúdico é compreendido como dimensão educativa, de motivação onde se descobre e alavanca o potencial de cada ser, provavelmente quem brinca apresenta sua inteligência. A luz dos estudos de G. Bruogére (2010), os brinquedos e as brincadeiras são ações aprendidas, que se aprende a brincar brincando com o outro, a partir dos estímulos recebidos do meio que cerca essa criança e, certamente o 
conjunto dessas interações é que forma a compreensão da cultura lúdica. G. Bruogére (2010) assevera que:

O brinquedo, em contra partida, não parece definido por uma função precisa, Trata-se antes de tudo, de um objeto que a criança manipula livremente, sem estar condicionada às regras ou a princípios de utilização de outra natureza... O brinquedo é um objeto infantil... Com certeza podemos dizer que a função do brinquedo é a brincadeira. (p.13).

Reflete-se sobre o pensamento acima e verifica-se que o papel do brinquedo não é algo linear, que é sério sem mobilidade, não indo mais além, o brinquedo tem o poder de passear sobre esses fatores, já que é um objeto palpável que os menores se libertam e dão diversos significados a uma peça lúdica atribuindo-lhe valor construtivo, a base do seu desenvolvimento é a função do brinquedo. Pois a brincadeira nesse contexto só é possível com a presença do objeto (brinquedo).

As brincadeiras são fatores cruciais no processo de ensino aprendizagem e, ao longo das atividades lúdicas se permiti oferecer objetos que possam despertar as relações intelectuais, incentivando a criança a construir e reconstruir novos conhecimentos, elevando a sua curiosidade e desenvolvendo atitudes, que envolvam bons momentos, pois é diante das brincadeiras que a criança pode revelar sentimentos de acordo com as experiências vivenciadas em sua rotina. É no aproveitamento dos brinquedos que a criançada faz do seu tempo livre uma enorme criação de saberes, entrando neste momento o papel do adulto frente a esse recurso pedagógico, que será de enfatizar o resgate do tempo do brincar infantil. O sujeito através do brincar tem a possibilidade de falar o que ela não consegue dizer diretamente, com o lúdico a criança tem essa oportunidade de se comunicar, principalmente na educação infantil, podem-se destacar aqui revelações por meio dos desenhos, dos gestos, por exemplo, podendo compartilhar suas experiências diante das suas próprias ilustrações, sabe-se que neste contexto, o brincar é atribuído de caráter livre e espontâneo, de acordo com G. Bruogére (2010).

Com seu valor expressivo, o brinquedo estimula a brincadeira ao abrir possibilidades de ações coerentes com a representação: pelo fato de representar um bebê, uma boneca bebê desperta atos de carinho, de troca de

RC: 98339

Disponível em:

https://www.nucleodoconhecimento.com.br/educacao/contextualizando-o-ludico 
roupa, de dar banho é o conjunto de atos ligados a maternagem. Porém não existe no brinquedo uma função de maternagem; há uma representação que convida a essa atividade num fundo de significação dado ao objeto num meio social de referência. (p.15-16).

Pode-se refletir que o brinquedo incentiva e auxilia no que tange a significação e sua representação, no qual a criança que brinca de mãe e filha, o brinquedo passa ser a filha enquanto a própria criança conquista o papel de mãe, com essa tarefa a brincadeira se torna cada vez mais verdadeira no imaginário da criança, por isso a brincadeira é construtora de saberes e habilidades, pensa-se que o sujeito ainda pequeno quando brinca, representando papeis estar ao mesmo tempo desenvolvendo, a linguagem, a coordenação motora e a percepção visual, interagindo diante do universo e realizando seus desejos por meio de suas experiências. Ainda com G. Bruogére (2010).

A infância é consequentemente, o momento de aquisição de imagens e de representações diversas que transitam por diferentes canais. As suas fontes são muitas. O brinquedo é, com suas especificidades, uma dessas fontes. Se ele traz para a criança um suporte de ação, de manipulação, de conduta lúdica, traz-Ihe, também, formas e imagens, símbolos para serem manipulados. (p. 42).

Se analisarmos as consequências desse entendimento o brinquedo enquanto aprendizagem social permite as relações entre as imagens, os símbolos e os materiais são fontes que permitem a observação e a descoberta, motivando na formação da conduta do brincar e de representar e dando oportunidades de domínio e preensão desses símbolos.

\section{COLETA DE DADOS, RESULTADOS E DISCUSSÃO}

O atual trabalho teve como coleta de dados uma pesquisa de campo, onde utilizamos como instrumento de coleta um questionário que continha quatro perguntas abertas, tendo a contribuição de um grupo de três professoras que atuam na rede municipal de Jaboatão. As educadoras atuam na educação infantil por mais de 10 anos, e são licenciadas em pedagogia, por isso acreditamos que as mesmas

RC: 98339

Disponível em:

https://www.nucleodoconhecimento.com.br/educacao/contextualizando-o-ludico 
estavam preparadas para dialogar com nossas indagações; a participação das professoras foi de grande valia para o aprimoramento e concretização do estudo.

As educadoras se envolveram em nossa pesquisa, pois percebemos que elas gostaram bastante da temática, por adotar o lúdico em suas ações pedagógicas e, por esse motivo foram capazes de responder com eficiência o questionário, oferecendo saberes importante e enriquecedor para o trabalho em foco, fora uma participação grupal onde foram necessárias três visitas para a conclusão da coleta de dados e, a partir desse momento analisou-se os dados. E, chegamos a uma percepção do quanto o brincar contribui no desenvolvimento infantil, que o brinquedo é uma ferramenta primordial no processo de ensino aprendizagem, agindo positivamente na construção de novos conhecimentos e descobertas. G. Brougére (2010, p.88-89).

Entretanto, o brinquedo é mais do que um instrumento de brincadeira. Traz para a criança, não só um meio de brincar, mas também imagens, representações, universos imaginários. Ele estrutura o conteúdo da brincadeira enquanto a criança brinca.

No pensamento de G. Brougére o brinquedo é peça fundamental na liberdade da brincadeira, com Kishimoto apud Penteado, (2011, P.189) "a brincadeira é o lúdico em ação", compreende-se em Kishimoto que se deve cultivar a brincadeira da criança, a liberdade do brincar, pois é o momento em que a criança representa , imagina e revela saberes, abrindo portas para uma multiplicidade de relações e reflexão.

As professoras revelaram durante a discussão que as brincadeiras incentivam a interação das crianças umas com as outras, aprende a se relacionar, estimulando a imaginação, motivando a criatividade, a socialização, além de convidar a criança para adentrar num mundo de representação e construção, conquistando gradualmente sua autoestima, assim como podemos constatar na fala das três professoras a seguir.

O lúdico é importante, pois contribui, auxiliando no processo de ensino aprendizagem em todos os aspectos, cognitivo, motor, social e na afetividade,

RC: 98339

Disponível em:

https://www.nucleodoconhecimento.com.br/educacao/contextualizando-o-ludico 
contribuindo para a construção da autonomia. É uma forma positiva já que o brincar desperta na criança a vontade de aprender, estimulando sua criatividade, criticidade, e com isso desenvolve seu lado criativo e inventivo, digamos que o brincar é uma ponte que caminha, guiando para as descobertas.

Pode-se perceber diante do relato das educadoras que o brincar é um recurso valioso e, serve como base para buscar novos saberes. Verifica-se então que, assim como se aprende a realizar uma tarefa, a brincadeira também é uma ação construída no meio sócio cultural. O brinquedo nesse sentido é um objeto possuidor de definições, por isso tem forte valor cultural, (BROUGÈRE, 2010).

As professoras demonstraram diante das discussões que quando a criança brinca, pega um objeto (brinquedo) dar início logo a uma brincadeira, ela simboliza cria, interage e com isso acontece à aprendizagem em meio à ludicidade, pois, através do lúdico a criança cresce e aprende com mais confiança e alegria.

\section{CONSIDERAÇÕES FINAIS}

Esta pesquisa fora de grande valia, pois se pode perceber o quanto o lúdico contribui no processo de ensino aprendizagem de crianças menores e, que brinquedo e brincadeiras são essenciais no desenvolvimento das habilidades. Nos estudos dos teóricos apresentados no decorrer deste trabalho em especial G. Brougère, mudamos conceitos a respeito do brincar e do brinquedo. Percebemos que a brincadeira é uma tarefa aprendida, já que se aprende a brincar no contexto sociocultural, pois dependendo do gral de incentivo esse resultado será mais ou menos positivo na formação de sujeitos éticos e, que possam agir de maneira respeitosa para o bem estar da sociedade. Enquanto o objeto gracioso, consequentemente viabiliza a brincadeira, já que desencadeia diversas situações e representação.

Ao longo desse estudo podemos pesquisar e fazer uma análise da relevância do brincar na educação infantil, este trabalho teve como tema principal, contextualizando o Lúdico em Sala de Aula e sub tema. Qual a Importância do

RC: 98339

Disponível em:

https://www.nucleodoconhecimento.com.br/educacao/contextualizando-o-ludico 
Brincar na Educação Infantil entre 03 - 05 anos? Verifica-se que a ação lúdica quando oferecida à criança nessa faixa etária é primordial no crescimento e no desenvolvimento do sujeito.

Percebe-se de maneira bastante clara, que quando a criança aprende brincando ela encontra um universo prazeroso e alegre. O prazer toma conta de cada garoto contagiando a todos e, o caminho da escola é percorrido lado a lado com alegrias e vontade de chegar logo no âmbito escolar, pois a criança sabe que ao chegar ao espaço escolar encontrará várias atividades graciosas que irão aprender brincando e, provavelmente não desistirá de frequentar a escola e nem tampouco de estudar.

O brincar concretiza as fantasias e, a concepção da criança é como um grande rio, que se alimenta por meio das águas, que deságua no mesmo ao caminhar por uma grande trilha, aguçando o imaginário e a curiosidade das crianças pequenas, fortalecendo a memória e abrindo portas para o mundo das descobertas e da invenção.

Verificamos que o jogo é uma ferramenta fundamental no processo de ensino aprendizagem, trazendo contribuições na socialização e na construção de conceitos contribuindo para o crescimento da pessoa, quem brinca geralmente convida alguém a participar da brincadeira, e dificilmente a criança aceita brincar cozinha interagindo apenas com o objeto, quando há outra pessoa por perto. A ludicidade certamente procede momentos imaginária, da mesma forma vai conduzindo uma norma. (BONTEMPO apud KISHIMOTO 2011). Considera-se uma forma de idear o jogo de papéis. O lúdico tem um caráter envolvente, alegre, coletivamente que conduz a participação. A importância do ato de brincar vai além da simples distração, dando possibilidade de aprender a se organizar e socializar-se, construindo relações duradouras e transportando as amizades para a fase adulta. Pensa-se que os brinquedos não trazem as cores aleatoriamente, esses objetos têm cores berrantes, picantes, chamativa com o intuito de acionar o processo cognitivo da criança. 
Analisa-se que toda criança gosta quando se fala de brinquedo e brincadeira próxima delas, se percebe que todas ficam radiantes e, com um sorriso estampado no rosto, gostoso de ser observado. As ações pedagógicas ou o fazer docente nas instituições de educação infantil dever ser sistematizadas frente o brincar, querendo enfatizar o tema lúdico, no processo de ensino aprendizagem das crianças, tem e deve ser abordado periodicamente, abrindo larga discussão e se tornando inspiração para o trabalho com a cultura divertida e, que novas ideias venham a surgir ampliando o repertório dos brinquedos e das brincadeiras, que possam abrir um leque de confiança entre todos, tornando as crianças felizes e saudáveis, que construam imagens em cada contexto social conforme o seu modo de ser de, se comunicar.

Para tanto, digamos que é no brincar que encontramos a rota do sucesso e a busca de uma ótima pessoa, como profissional, alguém que nutre ou cativa as relações no qual fazem parte de sua vida trazendo-lhe e fazendo germinar prazer, conforto, amizades, consideração, carinho, amor e tanto outras realizações, que possam ser dilatadas na conquista dos espaços, respeitando e sendo ético em suas atitudes. As brincadeiras são fontes de alegrias, elas vão além do aprender, viabilizando o caminho do presente e aspirando a um futuro harmonioso.

Em sua pesquisa Ribeiro (apud KISHIMOTO, 2011), O gracioso viabiliza o sujeito brincante conteúdos culturais no qual a jocosidade. Discutindo com o pensamento, as brincadeiras descortinam outras atividades lúdicas, pois a partir de uma dessa ação a criança constrói de forma gradual o seu próprio aprendizado e certamente a formação de conceitos. O objeto gracioso tende a proporcionar vertentes no que se refere o processo de aprendizagem no decorrer da primeira etapa da educação básica na construção divertida da promoção da cultura graciosa, uma vez que, quem brinca aprende de forma confiante.

Pensa-se que cada objeto ao surgir num determinado momento e, através de sua exploração vai ter um sentido diferente no cotidiano da criança. Se percebe que é no decorrer de um divertimento que o indivíduo tende a exerce seu poder de se lançar

RC: 98339

Disponível em:

https://www.nucleodoconhecimento.com.br/educacao/contextualizando-o-ludico 
em diversos movimentos de mutações e experimentação de cada símbolo, $\mathrm{n}$ que tange cada configuração. Em uma breve análise, o brinquedo estar impregnado da cultura construtiva, um brinquedo que passa a representar outra realidade diante, da manipulação ativa do indivíduo sobre o brinquedo. Utensilio valioso rumo ao processo de desenvolvimento da criança, em especial aqui entre quatro e cinco anos.

A luz do atual estudo pode-se perceber de maneira clara visto que, quem brinca quando pequeno, se permite a novas experiências, descobertas e horizontes. $O$ brincar convida tanto o adulto como a criança a conviver e a dividir do mesmo esforço, plantando a semente do afeto. Logo caminha para uma grande amizade, num mundo repleto de imaginação colorida, em que a afetividade se une com o brincar e, se transforme num universo prazeroso, no desenvolver, no participar e no aprender sadiamente dessa forma, o sujeito vai se preparando para atua na corporação de maneira ativa e sociável.

Reflete-se, portanto que, a prática pedagógica no qual o brincar seja pensando e aplicado no contexto infantil tende a viabilizar a socialização vigorosa, minimizando a cultura do individualismo, possibilitando sonhos e provavelmente fantasiar cada vez mais alto, aflorarando o pensamento de cada uma delas, motivando a criatividade e transformando essa criança em uma pessoa mais generosa e gentil que entenda desde muito cedo o verdadeiro valor das coisas, sejam esses, do mais simples até o mais elaborado, e também que seja capaz de plantar a semente da gentileza contribuindo para mudar o mundo de cada pessoa.

Com esse trabalho que acabamos de realizar espera-se que ele possa servir de fonte de pesquisa para futuros pesquisadores, e que o utilizem como fundamentação teórica, mudando conceitos a respeito da temática na primeira infância. Foi por meio deste estudo que nos fortalecemos e fortificamos nossos saberes, ostentando com firmeza a importância de que, o brincar é preciso, e essa prática pedagógica deve ser refletida e aplicada na sala de aula da educação infantil, porque nessa perspectiva quem brinca mostra a competência da inteligência e sendo assim, a 
criança expressa suas ideias e sentimentos, valendo salientar, que os brinquedos e as brincadeiras agem de forma colaborativa, no mantimento e no fortalecimento do desenvolvimento infantil, criando recursos para que as potencialidades da primeira infância sejam alcançadas e, que seja possível um planejamento da ação pedagógica através do brincar educativo.

As brincadeiras se são algo que se aprende na interação social, é interessante que se ensinem brincando, essência colaborativa amente fio condutor e fonte de conhecimento, e que se possam guiar à criança em sua idade tenra, que os sonhos delas são possíveis de serem realizados, uma vez que, o brincar seja incorporado no processo de ensino aprendizagem.

\section{REFERÊNCIAS}

AMARO, Ana, PÓVOA, Andreia, MACEDO, Lúcia. Metodologias de Investigação em Educação: arte de fazer questionário. 204/2015.11p. Relatório. Faculdade de Ciências da Universidade do Porto. Disponível em <http://www.unisc.br/portal/upload/com> acesso em 03 de março às 21 h30min.

ANDRADE, Maria Margarida. Introdução á Metodologia do Trabalho Científico: elaboração de trabalhos na graduação. 10ª edição. São Paulo. Atlas S.A. 2010.

ANTUNES, Celso. Inteligência Múltipla e Seus Jogos: inteligência lógicamatemática. Editora. Vozes, 4ํe edição, vol.6 Petrópolis RJ. 2012.

BOMTEMPO, Edda. A brincadeira de faz de conta: lugar do simbolismo, da representação, do imaginário. In:__Jogo, Brinquedo, Brincadeira e a Educação, 14ª Edição, Petrópolis ed. Vozes, 2011.p.67.

BRUOGÉRE, Gilles. Brinquedo e cultura. 8ª ed. São Paulo. Cortez, 2010.

RC: 98339

Disponível em:

https://www.nucleodoconhecimento.com.br/educacao/contextualizando-o-ludico 
CORREA Bruna. Jogos. Quando, como e por que usar: uma criança de 2 anos tem um amigo imaginário. Como agir? São Paulo. Nova escola n.260 p.20, mar.2013.

KISHIMOTO, Tezuko Morchida. Jogos Infantis, O jogo a criança e a educação, 13를 Edição, ed. Vozes, Petrópolis 2006.

Jogo, Brinquedo, Brincadeira e a Educação. 14ª ed. São Paulo, Cortez, 2011.

LINN, Susan. Em Defesa do Faz de Conta. Editora, BetsSaller. Rio de Janeiro 2010.

PENTEADO, Heloísa Dupas. Jogo e Formação de professores: vide psicodrama pedagógico: In: KISHIMOTO, Tezuko Morchida. Jogos Infantis, 0 jogo a criança e a educação, 14ª Edição, Petrópolis ed. Vozes, 2011.p.189.

PINHEIRO, Edson José. et al. Apostilas Solução, a solução para seu concurso! ed. 30 anos, Prefeitura do Recife, edital 2014.

Referencial Curricular Nacional Para Educação Infantil. Vol.1. Brasília 1998.

RIBEIRO, Maria Luiza Sprovieri. O jogo na organização curricular para deficientes mentais. In: Jogo, Brinquedo, Brincadeira e a Educação, 14a Edição, Petrópolis ed. Vozes, 2006.p.153.

TRIVINÕS, Augusto N. S. Introdução à Pesquisa em Ciências Sociais: a pesquisa qualitativa em educação. São Paulo: atlas 1987.

\section{APÊNDICE}

Faculdade Joaquim Nabuco

RC: 98339

Disponível em:

https://www.nucleodoconhecimento.com.br/educacao/contextualizando-o-ludico 
Esta pesquisa teve como tema Contextualizando o Lúdico em Sala de Aula: Qual Importância do Brincar na Educação Infantil entre 03 a 05 anos. Os questionamentos e perspectivas foram desenvolvidos por Josefa de Barros Barbosa do Nascimento Mirian Maria da Silva, alunas do curso de Pedagogia unidade Recife.

Entrevista

Faixa etária das entrevistadas 35 - 40 anos.

Sexo feminino

Atuam na área a mais de dez anos.

São todas graduadas em Pedagogia e pôs graduada. .

Qual a contribuição dos brinquedos e das brincadeiras no desenvolvimento infantil?

Qual a contribuição dos jogos para a aprendizagem?

Vocês trabalham com jogos na sala de aula aqui na escola?

Qual a contribuição do brincar de faz de conta na aprendizagem?

Enviado: Junho, 2020.

Aprovado: Outubro, 2021.

RC: 98339

Disponível em:

https://www.nucleodoconhecimento.com.br/educacao/contextualizando-o-ludico 